\title{
The Sir William Macewen Lecture
}

On 8 August 1888 a young Glasgow surgeon delivered an address that caused a sensation at the annual British Medical Association meeting, held in the Bute Hall, University of Glasgow. William Macewen described the work that was to lead an illustrious successor to comment "to Macewen belongs the distinction of having been the chief pioneer in cranio-cerebral surgery", (Harvey Cushing, 1927).

Macewen was born in 1848, on the Isle of Bute, graduated from the University of Glasgow in 1870 and in 1874 joined the surgical staff of the Glasgow Royal Infirmary. There he took a leading role in the evolution of modern aseptic surgery from the concept of antisepsis, introduced by the hero of his student days, Joseph Lister. Macewen was also aware of the accumulating evidence of the existence of the circumscribed areas of the brain, each subserving a defined function, that was emerging from the work of Broca (1861), Hughlings Jackson (1869), Fritz and Hitzig (1870) and Sir David Ferrier (1873).

Macewen was the first to apply this new knowledge of neurological principles to plan intracranial operations, which until then had been guided only by external signs of the disease. In 1879 he operated successfully on a0 subdural haematoma, (Br Med J 1879;2:1022), and an intracranial tumour (Glasgow Medical Journal 1879;12: 210). By 1888 Macewen had accumulated the experience that led a contemporary writer to comment "Results have been obtained by Dr Macewen which would never have been dreamt of a quarter of a century ago and whic must have caused the older school of practitioners to remodel their physiology". (Medical Press and Circulat 2 January 1889).

Macewen had established the feasibility, safety and success of what thereafter could properly be calle "neurological surgery". A century after his address, it was commemorated by a lecture delivered of 23 September 1988 during the meeting of the Society of British Neurological Surgeons in the Royal College of Physicians and Surgeons in Glasgow. The orator was Professor Olle Lindvall, University of Lund. His account of experimental and clinical studies of the transplantation of neural tissue provides a masterly overview of current knowledge and, perhaps, a vision of the next century of neurosurgery. 